\title{
Tuning a bi-enzymatic cascade reaction in Escherichia coli to facilitate NADPH regeneration for $\varepsilon$-caprolactone production
}

\author{
Jinghui Xiong ${ }^{1 \dagger}$, Hefeng Chen ${ }^{1 \dagger}$, Ran Liu ${ }^{1}, \mathrm{Hao} \mathrm{Yu}^{2}$, Min Zhuo ${ }^{1}$, Ting Zhou ${ }^{1}$ and Shuang $\mathrm{Li}^{1 *}$ (i)
}

\begin{abstract}
$\varepsilon$-Caprolactone is a monomer of poly( $\varepsilon$-caprolactone) which has been widely used in tissue engineering due to its biodegradability and biocompatibility. To meet the massive demand for this monomer, an efficient whole-cell biocatalytic approach was constructed to boost the $\varepsilon$-caprolactone production using cyclohexanol as substrate. Combining an alcohol dehydrogenase (ADH) with a cyclohexanone monooxygenase (CHMO) in Escherichia coli, a self-sufficient NADPH-cofactor regeneration system was obtained. Furthermore, some improved variants with the better substrate tolerance and higher catalytic ability to $\varepsilon$-caprolactone production were designed by regulating the ribosome binding sites. The best mutant strain exhibited an $\varepsilon$-caprolactone yield of $0.80 \mathrm{~mol} / \mathrm{mol}$ using $60 \mathrm{mM}$ cyclohexanol as substrate, while the starting strain only got a conversion of $0.38 \mathrm{~mol} / \mathrm{mol}$ when $20 \mathrm{mM}$ cyclohexanol was supplemented. The engineered whole-cell biocatalyst was used in four sequential batches to achieve a production of $126 \mathrm{mM} \varepsilon$-caprolactone with a high molar yield of $0.78 \mathrm{~mol} / \mathrm{mol}$.
\end{abstract}

Keywords: Whole-cell biocatalysis, RBS design, NADPH regeneration, Cyclohexanol, $\varepsilon$-caprolactone

\section{Introduction}

As people face the global changes in energy, resources, and the environment, biocatalysis attracts great attentions in chemical, pharmaceutical and energy industries because of its high activity, selectivity, specificity and low energy requirements. Oxidoreductases are one class of the most important enzymes ( $\sim 25 \%$ of all enzymes) responsible for the inter-molecule electron transfer (Hollmann et al. 2011). However, many enzymatic redox applications are limited by the dependence on cofactors as hydrogen source, such as nicotinamide adenine dinucleotide (NADH) and its phosphorylated form (nicotinamide adenine dinucleotide phosphate, NADPH). Considering the high cost, stoichiometric usage and instability of $\mathrm{NAD}(\mathrm{P}) \mathrm{H}$, an effective regeneration system

\footnotetext{
*Correspondence: shuangli@scut.edu.cn

† Jinghui Xiong and Hefeng Chen contributed equally to this work

${ }^{1}$ School of Biology and Biological Engineering, South China University

of Technology, Higher Education Mega Center, Guangzhou 510006, China

Full list of author information is available at the end of the article
}

is essential for the industrial implementation of oxidoreductases. It has been accepted as a rule of thumb that less than $0.1 \mathrm{~mol} \%$ of the cofactor used appears economically (Hollmann et al. 2011).

Many critical reviews focused on the cofactor NAD $(\mathrm{P})$ $\mathrm{H}$ regeneration have been documented by researchers (Quinto et al. 2014; Spaans et al. 2015; Wang et al. $2017 \mathrm{a}, \mathrm{b})$. In general, the regeneration of cofactor $\mathrm{NAD}(\mathrm{P}) \mathrm{H}$ can be conducted via enzymatic, chemical, photocatalytic and electrochemical approaches. Using inorganic salts with high redox potential or cofactor analogues, the $\mathrm{NAD}(\mathrm{P}) \mathrm{H}$ could be regenerated chemically (Wu et al. 2013). However, it has not been widely used for its inherent issues, such as low transformation efficiency, enzyme deactivation, waste generated, etc. Although photocatalytic and electrochemical methods attracted many attentions in recent years, more further studies and investigations are needed for industrial application due to its poor efficiency, bad compatibility and low selectivity (Hildebrand et al. 2008; Weckbecker 
et al. 2010). So far, only the enzymatic regeneration method has been demonstrated to be feasible and applied on industrial scale for its excellent compatibility with the target biocatalytic process (Sun et al. 2017; $\mathrm{Xu}$ et al. 2019; Zhang et al. 2019). In particular, the combination of redox enzymes (Wu et al. 2013), such as formate dehydrogenase and glucose dehydrogenase, in a linear cascade fashion has received increasing attentions because it does not need isolating intermediates.

$\varepsilon$-Caprolactone, with global annual production of multi-kilotons, is an important non-toxic compound used as a monomer for biodegradable, thermoplastic and elastomeric polymer synthesis(Pathak and Navneet 2017). In industry, $\varepsilon$-caprolactone is synthesized by chemical Baeyer-Villiger reaction using peroxycarboxylic acids as oxidant (ten Brink et al. 2004). In the early 1990s, Willetts et al. first reported an enzymatic approach to the lactone synthesis in a linear cascade fashion in vitro (Willetts et al. 1991). Nowadays, this cascade method has been applied to the $\varepsilon$-caprolactone biosynthesis, in which the oxidation starts from a readily available compound cyclohexanol by an alcohol dehydrogenase $(\mathrm{ADH})$ and further undergoes the oxidation of cyclohexanone by a cyclohexanone monooxygenase (CHMO) (Mallin et al. 2013; Ménil et al. 2019; Scherkus et al. 2016; Schmidt et al. 2015b; Staudt et al. 2013; $\mathrm{Xu}$ et al. 2019). In this cascade reaction, the consumption of cyclohexanol to cyclohexanone catalyzed by ADH was accompanied by the production of $\mathrm{NADPH}$, and the production of $\varepsilon$-caprolactone from cyclohexanone by CHMO was also accompanied by the consumption of NADPH (Fig. 1a). However, it is still debatable whether the catalysts are isolated enzymes, acellular extracts, or whole cells. From a practical point of view, whole cells containing all the enzymes in the same organism are preferred since external cofactor regeneration is not necessary. Moreover, tedious and high-cost enzyme purification processes are no longer required (France et al. 2017). However, it is still challenging to achieve satisfactory results in controlling the enzyme ratio in the cascade reaction system (Gandomkar et al. 2019; Ménil et al. 2019; Milker et al. 2017; Scherkus et al. 2017; Xu et al. 2019).

Herein, we systematically designed and constructed several mutants through engineering ribosome binding site (RBS) to achieve cofactor self-sufficient for $\varepsilon$-caprolactone production in E. coli. As a result, an optimized strain dramatically increased the $\varepsilon$-caprolactone molar yield and substrate tolerance. Finally, a sequential batch reaction was applied to further increase the production titer through the wholecell biocatalytic approach.

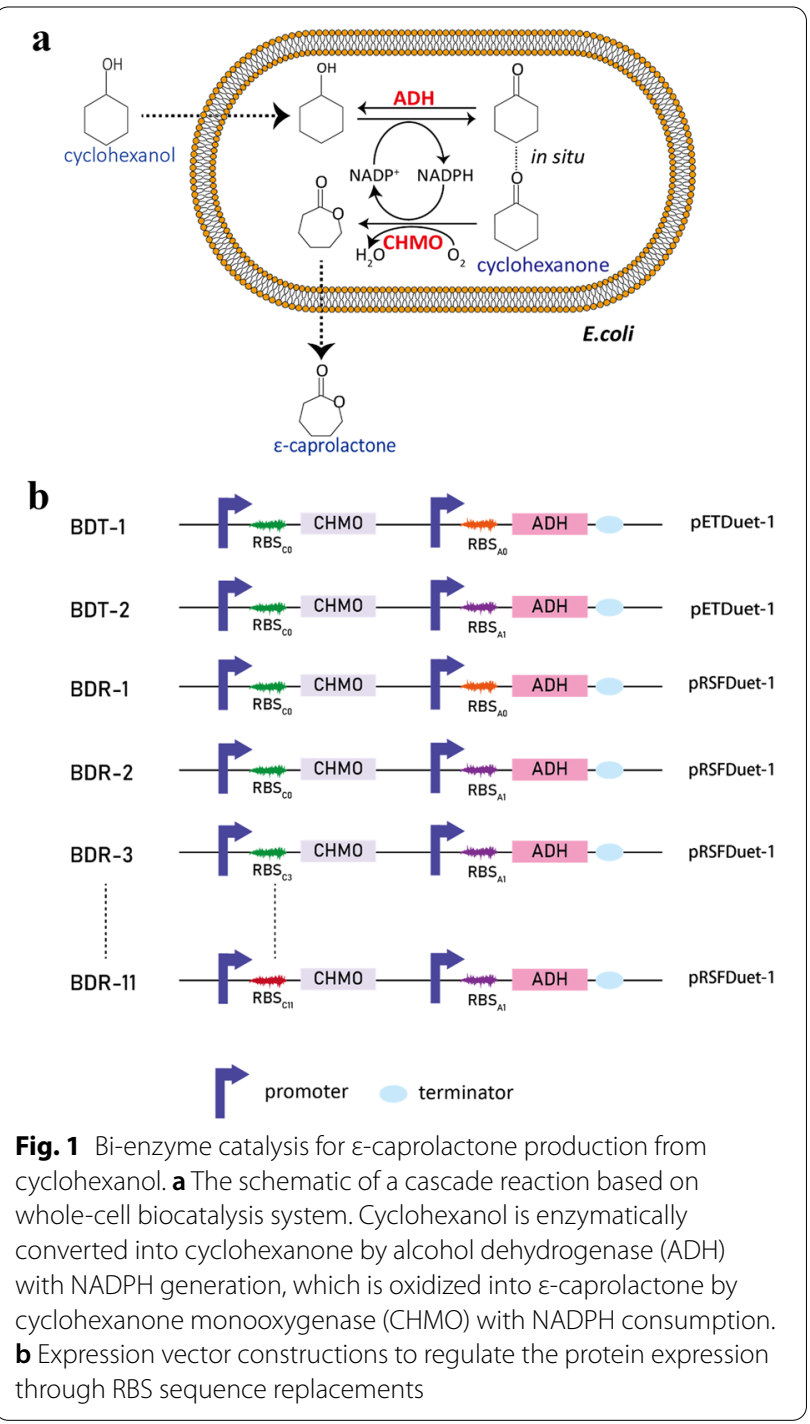

\section{Material and methods}

Chemicals, strains and culture conditions

Cyclohexanol, cyclohexanone and $\varepsilon$-caprolactone were purchased from Sangon Biotech (Shanghai, China). The restriction enzymes and T4 DNA ligase were obtained from Thermo Fisher Scientific (Pittsburgh, PA, USA). DNA Polymerase of PrimeSTAR HS was from TaKaRa (Dalian, China). Plasmids of pETDuet-1 and pRSFDuet-1 (Novagen) were used for co-expression of the two genes.

E. coli DH5 $\alpha$ was used for expression vector construction and plasmid maintenance. The strain E. coli BL21(DE3) was used as host for all expression experiments. E. coli cells were cultured in Luria-Bertani (LB) medium containing $10 \mathrm{~g} / \mathrm{L}$ peptone, $10 \mathrm{~g} / \mathrm{L}$ sodium chloride, and $5 \mathrm{~g} / \mathrm{L}$ yeast extract with appropriate antibiotics (50 $\mu \mathrm{g} / \mathrm{mL}$ kanamycin or $100 \mu \mathrm{g} / \mathrm{mL}$ ampicillin). 


\section{Plasmid construction}

The CHMO gene with quadruple mutant (GenBank Accession No. BAA86293.1) (Schmidt et al. 2015a) encoding cyclohexanone monooxygenase and the $A D H$ gene (GenBank Accession no. AY267012.1) encoding alcohol dehydrogenase were both synthesized and cloned into pUC57 by Sangon Biotech (Shanghai, China) after codon optimization for expression in E. coli.

The $C H M O$ and $A D H$ were amplified by PCR using CHMO-f/CHMO-r and ADH-f/ADH-r primer pairs and integrated into the pETDuet-1 vector at the Nco I/Pst I and Nde I/Xho I sites, yielding pETD-CHMO and pETD$\mathrm{ADH}$, respectively. The dual-expression vectors of $\mathrm{pET}$ COAO and pRSF-COA0 were both constructed using the similar restriction enzyme digestion and ligation methods. All the constructed vectors and recombinant strains are listed in the Additional file 1: Table S1, and the corresponding amplification primers are shown in Additional file 1: Table S2.

We designed a 12-variant RBS library to tune expression ratio of the bi-enzyme cascade across a 500-fold range according the RBS Calculator v2.0 model (Additional file 1: Table S3) (De Novo DNA 2018; Salis et al. 2009). For RBS sequence change, a recombination-based cloning strategy was carried out using the ClonExpress II One Step Cloning Kit (Vazyme, Nanjing, China). All clones were sequenced for verification by Sangon Biotech (China).

\section{$\mathrm{ADH}$ and $\mathrm{CHMO}$ expression}

Seed cultures were prepared by the inoculation of a single colony into $10 \mathrm{~mL} \mathrm{LB}$ medium supplemented with appropriate antibiotics and incubated at $37{ }^{\circ} \mathrm{C}, 220 \mathrm{rpm}$ overnight. The overnight cultures were transferred into fresh LB medium $(2 \%, \mathrm{v} / \mathrm{v})$ and cultivated in $500-\mathrm{mL}$ flasks. At a range of the cell density $\left(\mathrm{OD}_{600}\right)$ between 0.5 and 0.7 , isopropyl $\beta$-D-1-thiogalactopyranoside (IPTG) was added to a final concentration of $0.5 \mathrm{mM}$ for the induction of enzymes expression. After incubating at $30{ }^{\circ} \mathrm{C}$ with $180 \mathrm{rpm}$ in an orbital shaker for $7 \mathrm{~h}$, the recombinant $E$. coli cells were harvested by centrifugation at $3050 \mathrm{rpm}$ for $30 \mathrm{~min}$ and subjected to the activity evaluation.

Sodium dodecyl sulfate-polyacrylamide gel electrophoresis (SDS-PAGE) was used to detect the expression level.

\section{Whole-cell enzyme activity assay}

The oxidation of NADPH assay was applied to determine the activities of ADH and CHMO in E. coli cell lysates (Schmidt et al. 2015b). Normalized $10 \mathrm{OD}_{600}$ cells was suspended in $50 \mathrm{mM}$ sodium phosphate buffer $(\mathrm{pH}$ 7.5) to a final volume of $1 \mathrm{~mL}$ and lysed by sonication.
The supernatants were collected by centrifugation at $12,000 \mathrm{rpm}$ at $4{ }^{\circ} \mathrm{C}$ for $15 \mathrm{~min}$. Catalytic reactions were conducted in a final volume of $200-\mu \mathrm{L}$ system containing $187 \mu \mathrm{L} 50 \mathrm{mM}$ sodium phosphate buffer ( $\mathrm{pH} 7.5$ ), $1 \mu \mathrm{L}$ of $50 \mathrm{mM}$ NADPH stock solution, and $10 \mu \mathrm{L}$ crude cell lysate with $2 \mu \mathrm{L}$ substrate stock. $1 \mathrm{mM}$ acetophenone or $1 \mathrm{mM}$ thioanisole were used as the substrate for measurements of $\mathrm{ADH}$ or $\mathrm{CHMO}$ activity, respectively. After 2 min of incubation at room temperature, the initial consumption rates of NADPH were calculated and normalized as enzyme activities in crude cell lysate in $\mathrm{U} / \mathrm{mL}$ $(\mu \mathrm{mol} / \mathrm{min} / \mathrm{mL})$.

\section{$\varepsilon$-Caprolactone production through whole-cell catalysis}

The collected cell pellets were washed with a $20 \mathrm{mM}$ Tris-Cl buffer (pH 7.5) with $1 \% \mathrm{NaCl}$ and $1 \%$ dimethyl sulfoxide (DMSO) to a wet cell weight (WCW) of $100 \mathrm{~g} / \mathrm{L}$. This cell suspension was chilled in ice-water bath for $30 \mathrm{~min}$ and centrifuged again at $1050 \mathrm{~g}, 4{ }^{\circ} \mathrm{C}$ for $25 \mathrm{~min}$. Cell pellets were collected and resuspended in $20 \mathrm{mM}$ Tris-Cl buffer ( $\mathrm{pH}$ 7.5) containing $1 \% \mathrm{NaCl}$ yielding $10 \mathrm{~g}_{\mathrm{wcw}} / \mathrm{L}$ resting cell suspensions as whole-cell biocatalyst. The biocatalysis were carried out in $50 \mathrm{~mL}$ Erlenmeyer flasks containing $10 \mathrm{~mL}$ of the whole-cell biocatalyst supplemented with cyclohexanol as substrate at different concentrations. The flasks were sealed with Parafilm ${ }^{\circledR}$ and incubated at $25{ }^{\circ} \mathrm{C}, 120 \mathrm{rpm}$ for $16 \mathrm{~h}$.

Sequential fed-batch catalysis was conducted in 250$\mathrm{mL}$ flasks with reaction volume of $50 \mathrm{~mL}$. The recombinant cells were cultured, induced, collected and pretreated as described above. The initial reaction mixture, consisting of $20 \mathrm{mM}$ Tris- $\mathrm{HCl}$ buffer $(\mathrm{pH} 7.5)$ with $1 \% \mathrm{NaCl}$, resting cells $\left(10 \mathrm{~g}_{\mathrm{wcw}} / \mathrm{L}\right)$ and $40 \mathrm{mM}$ cyclohexanol, was incubated at $25{ }^{\circ} \mathrm{C}$ and $120 \mathrm{rpm}$ for $16 \mathrm{~h}$. Subsequently, cyclohexanol was fed to the reactor at a final concentration of $40 \mathrm{mM}$ at 16,32 and $48 \mathrm{~h}$.

Samples of $0.5 \mathrm{~mL}$ were taken and stored at $-20{ }^{\circ} \mathrm{C}$ for the determination of cyclohexanol, cyclohexanone, $\varepsilon$-caprolactone. All catalytic experiments were performed in triplicates.

\section{Analysis of cyclohexanol, cyclohexanone, $\varepsilon$-caprolactone} Aliquots of the reaction mixture $(500 \mu \mathrm{L})$ were taken and extracted using equal volume of ethyl acetate containing $2 \mathrm{mM}$ acetophenone as internal standard. The organic phase was collected after vigorous vortex for $15 \mathrm{~min}$ and centrifugation at $12,000 \mathrm{rpm}$ for $10 \mathrm{~min}$. The upper organic layer of the mixture was appropriately diluted with ethyl acetate, and then filtered with filter membrane $(0.22 \mu \mathrm{m})$ into the sample vials for analysis.

Gas chromatography (GC) analyses were performed using a Hewlett-Packard 7890 Gas Chromatography (Agilent) equipped with a HP-5 column (crosslinked 
5\% Ph-Me Siloxane; $30 \mathrm{~m} \times 0.32 \mathrm{~mm} \times 0.25 \mu \mathrm{m})$ and a hydrogen flame-ionization detector (FID). The temperatures of injector and detector were set as $250{ }^{\circ} \mathrm{C}$ and $280{ }^{\circ} \mathrm{C}$, respectively. $1 \mu \mathrm{L}$ sample was injected with a split ratio of 10:1 at a rate of $2 \mathrm{~mL} / \mathrm{min}$ in constant flow mode $(33.093 \mathrm{~cm} / \mathrm{s}$ linear velocity). Samples were run using the following program: the initial $\mathrm{GC}$ oven temperature was set to $37{ }^{\circ} \mathrm{C}$, then increased to $160{ }^{\circ} \mathrm{C}$ with a ramp rate of $10{ }^{\circ} \mathrm{C}$ per min, and the temperature finally was increased to $220{ }^{\circ} \mathrm{C}$ with a ramp rate of $20{ }^{\circ} \mathrm{C}$ per min. The concentrations of substrates and products were determined using internal calibration curves.

Chromatography coupled to mass spectrometry $(\mathrm{GC}-\mathrm{MS})$ analyses were performed on a $\mathrm{GC} /$ MS-HP7890 (Agilent) gas chromatography system equipped with a $5975 \mathrm{C}$ series mass selective detector (MSD) and a HP-5 column (crosslinked 5\% Ph-Me Siloxane; $30 \mathrm{~m} \times 0.32 \mathrm{~mm} \times 0.25 \mu \mathrm{m}$ ). The same GC oven temperature programs were used as described above for GC detection. MS data were recorded at $70 \mathrm{eV}(\mathrm{EI}), \mathrm{m} / z$ (rel. intensity in \%) as TIC, total ion current. The sample was analyzed in a mass/charge $(\mathrm{m} / \mathrm{z})$ range of $40-200$. Compounds in the samples were determined by comparing retention time and mass spectrometry GC/MS spectra to the commercially available chemical standards and mass spectrometry data from the NIST Standard Reference database.

The statistical analysis multiple $t$ tests were performed by GraphPad Prism 8.0. The false discovery rate (FDR) approach using two-stage step-up method of Benjamini, Krieger and Yekutieli was chosen for analysis. Significant difference was considered when $p$ value $<0.05$.

\section{Detection of NADPH/NADP ${ }^{+}$ratio in cells}

The ratio of NADPH/NADP ${ }^{+}$was detected using Coenzyme II NADP(H) Assay Kit (Comin, Suzhou, China). Samples at $0 \mathrm{~h}$ and $16 \mathrm{~h}$ during the whole-cell catalysis using $60 \mathrm{mM}$ cyclohexanol as substrate were taken for detection. All experiments were performed in triplicates.

\section{Results and discussion}

\section{$\mathrm{ADH}$ and $\mathrm{CHMO}$ expression and enzyme activity} determination

To balance the NADP $(\mathrm{H})$ regeneration and intermediate consumption during the $\varepsilon$-caprolactone bi-enzymatic synthesis, the ratio of $\mathrm{ADH}$ and $\mathrm{CHMO}$ is very important for their different specific activities and expression levels. A mutant of CHMO (C376L/M400I/T415C/A463C) with better stability at high temperatures from Acinetobacter calcoaceticus (Schmidt et al. 2015a) and ADH from Lactobacillus kefir were cloned into the MSC1 $\left(\mathrm{RBS}_{\mathrm{C} 0}\right)$ and MSC2 (RBS $\left.{ }_{\mathrm{A} 0}\right)$ in pETDuet-1, yielding pETD-CHMO and pETD-ADH, respectively (Fig. 1, Additional file 1:
Table S1). When vectors were transformed into E. coli BL21(DE3), the recombinant cells were cultured and induced by $0.5 \mathrm{mM}$ IPTG for the expression of cyclohexanone monooxygenase and alcohol dehydrogenase. After incubation for $7 \mathrm{~h}$, specific activities of $\mathrm{ADH}$ and $\mathrm{CHMO}$ in crude cell lysates were determined as 1.66 and $0.1 \mathrm{U} /$ $\mathrm{mL}$ in BDT-1, 2.9 and $0.2 \mathrm{U} / \mathrm{mL}$ in BDR-1, respectively. Apparently, there was a wide gap in the crude activities between $\mathrm{ADH}$ and $\mathrm{CHMO}$.

\section{ADH expression level alteration}

To balance the catalytic efficiency for ADH and CHMO in a co-expression vector, a reduction of the ADH expression level would be preferred. In the most cases, the translation initiation is the rate-limiting step in bacterial protein expression. The ribosome binding site (RBS) and some other regulatory RNA sequences are thought as effective elements for the control of translation initiation (Salis et al. 2009). It is generally accepted that a purine-rich Shine-Dalgarno (SD) sequence similar to 5'-GGAGG-3' located on RBS functions as a region with high affinity for the $30 \mathrm{~S}$ subunit binding. Mutation at the SD sequence could severely reduce the expression level of the target protein in E. coli (Ban et al. 2000).

In this study, a mutation of $\mathrm{G} \rightarrow \mathrm{C}$ at the $\mathrm{SD}$ sequence on $\mathrm{RBS}_{\mathrm{A} 0}$ controlling $\mathrm{ADH}$ expression was introduced (from $5^{\prime}$-GGAGA-3' to $5^{\prime}$-GCAGA-3'). The plasmids containing the $\mathrm{CHMO}$ and $\mathrm{ADH}$ expression cassettes based on pETDuet-1 and pRSFDuet-1 were constructed and transformed into E. coli BL21(DE3) cells separately, yielding BDT-1, BDT-2, BDR-1 and BDR-2 (Fig. 1). Different expression vectors containing variable SD sequences had little effects on the cell growth (Additional file 1: Table. S4). However, the specific activities in the crude cell lysates and SDS-PAGE picture clearly demonstrated the changes in the $\mathrm{ADH}$ and $\mathrm{CHMO}$ expression levels (Fig. 2a). Changes of purine to cytosine on SD sequence on $\mathrm{RBS}_{\mathrm{A} 0}$ caused the $\mathrm{ADH}$ activity reduction from $1.66 \mathrm{U} / \mathrm{mL}$ (BDT-1) to $0.66 \mathrm{U} / \mathrm{mL}$ (BDT-2) in pETDuet-1. On the contrary, an increase in CHMO activity based on pETDuet-1 was observed from $0.10 \mathrm{U} / \mathrm{mL}$ to $0.19 \mathrm{U} / \mathrm{mL}$. When using pRSFDuet-1 as the construction backbone, similar variation tendencies of expression levels and specific activities for ADH and CHMO were recorded. To be noted, whatever the SD sequence is, the expression levels of CHMO and ADH on pRSFDuet-1 were all higher than those on pETDuet-1. The copy number of pETDuet-1 plasmid containing ColE1 replicon was less than that of pRSFDuet-1 vector with RSF1030 replicon, which might lead to much lower expression levels of targets on pETDuet-1 than pRSFDuet-1 (Tolia and Joshua-Tor 2006). 


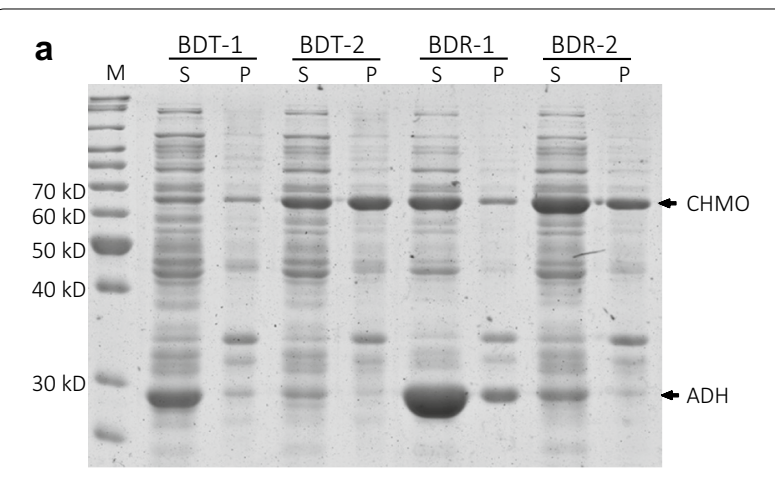

b

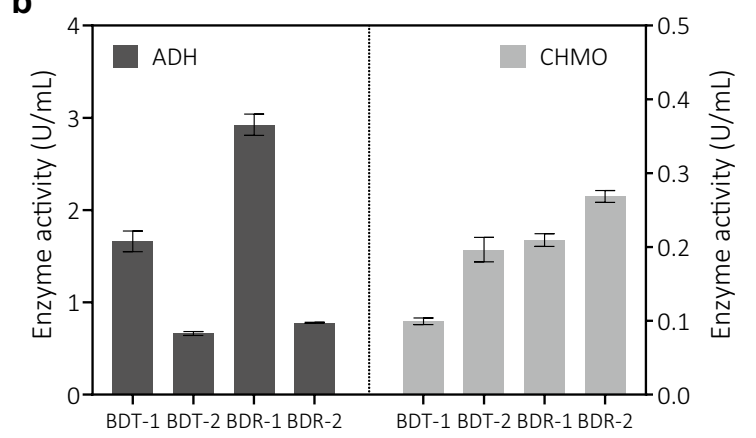

Fig. 2 Expression levels of E. coli BL21(DE3) containing alcohol dehydrogenase $(\mathrm{ADH})$ and cyclohexanone monooxygenase (CHMO) in the dual promoter vectors. a SDS-PAGE electropherogram. 10 $\mathrm{OD}_{600}$ Cells were collected by centrifugation and resuspended in $1 \mathrm{~mL}$ lysis buffer and subjected to sonication for cell lysis.

$S=$ supernatant fractions of cell lysates, $P=$ precipitates of cell lysates, $M=$ standard protein marker. The arrows indicate $\mathrm{CHMO}(62 \mathrm{kDa})$ and $\mathrm{ADH}(28 \mathrm{kDa})$, respectively. b Enzyme activity $(\mathrm{U} / \mathrm{mL})$ of $\mathrm{ADH}$ and $\mathrm{CHMO}$ for the four recombinant $E$. coli strains. Measurements were performed in three independent experiments

To evaluate the performance of the four bi-enzymatic cascades, whole-cell bioconversion of cyclohexanol to $\varepsilon$-caprolactone was carried out feeding with $20 \mathrm{mM}$ or $40 \mathrm{mM}$ of substrate cyclohexanol (Fig. 3 and Additional file 1: Fig. S1). For the strains of BDT-1 and BDR-1 containing the native SD sequence, only 8.5 and $11.9 \mathrm{mM}$ of $\varepsilon$-caprolactone were produced when $20 \mathrm{mM}$ of substrate cyclohexanol was fed. When the site mutation was introduced, $20 \mathrm{mM}$ of cyclohexanol was totally converted with an $\varepsilon$-caprolactone yield of 65.2 and $87.0 \%$ for BDT-2 and BDR-2, respectively. However, a small amount of cyclohexanone was detected in the reaction mixture. When the initial substrate concentration was increased to $40 \mathrm{mM}$, the differences in bi-enzymatic cascade reactions were even more pronounced (Fig. $3 \mathrm{~b}$ ). The performance of strain of BDT-1 and BDR-1 was not good enough, as the $\varepsilon$-caprolactone yields were dramatically decreased to less than $30 \%$. When the ADH expression levels were lowered, most of the cyclohexanol was oxidized with $\varepsilon$-caprolactone yields of 71.8 and $87.0 \%$ for BDT-2 and
BDR-2, respectively. Although the strain BDR-2 achieved the highest $\varepsilon$-caprolactone concentration as $34.8 \mathrm{mM}$, small amounts of cyclohexanol and cyclohexanone were still detected in the reaction mixture. The results indicate that the further tuning in the bi-enzyme tandem system is needed to improve the performance, especially at high concentrations of cyclohexanol substrate.

The activity ratio of ADH/CHMO is an important factor for the whole-cell synthesis of $\varepsilon$-caprolactone in the bi-enzymatic cascade biotransformation considering the $\operatorname{NADP}(\mathrm{H})$ balance. The highest $\varepsilon$-caprolactone yield was achieved at a ratio of $\mathrm{ADH} / \mathrm{CHMO}$ of 0.34 for the strain BDR-2. For the starting strain of BDT-1 and BDR-1, the ratios of $\mathrm{ADH} / \mathrm{CHMO}$ were in the range of 0.06-0.07. In the bi-enzymatic system, $1 \mathrm{~mol}$ of NADPH is produced through the ADH catalysis from cyclohexanol, accompanying $1 \mathrm{~mol}$ of NADPH consumed by CHMO to produce $1 \mathrm{~mol}$ of $\varepsilon$-caprolactone (Fig. 1). From the stoichiometry perspective, the closer to 1 the ratio of $\mathrm{ADH} / \mathrm{CHMO}$ is, the better the $\varepsilon$-caprolactone biosynthesis efficiency in the cascade reaction. Thus, it was speculated that the regulation of CHMO expression level might be beneficial to improve the $\varepsilon$-caprolactone activities in this tandem cascade catalytic reaction.

\section{CHMO expression level tuning}

In this study, a series of RBS sequences controlling CHMO expression were designed with different $\mathrm{T} 7$ RNAP translation rates according to the RBS Calculator V2.0 (Additional file 1: Table S3) (Espah Borujeni et al. 2014). After the replacements of RBS sequences, there was little difference in the ADH activity of different recombinant cells as expected. However, the CHMO activities were altered dramatically (Fig. 4). Generally, the expression levels of CHMO judged from SDS-PAGE were roughly consistent with the detected CHMO activities. And the expression levels of ADH changed insignificantly (Additional file 1: Fig. S2). When the translation rates were reduced, the activities of $\mathrm{CHMO}$ also decreased to different degrees $\left(\mathrm{RBS}_{\mathrm{C} 3}\right.$ and $\left.\mathrm{RBS}_{\mathrm{C} 4}\right)$. For the sequence replacements of $\mathrm{RBS}_{\mathrm{C} 5}, \mathrm{RBS}_{\mathrm{C} 7}, \mathrm{RBS}_{\mathrm{C} 10}$ and $\mathrm{RBS}_{\mathrm{C} 11}$ with faster RNAP translation rate, activities of CHMO were elevated by $25-60 \%$ compared with that of $\mathrm{RBS}_{\mathrm{C} 0}$. But a faster translation rate did not always indicate a relatively higher $\mathrm{CHMO}$ activities (e.g., $\mathrm{RBS}_{\mathrm{C} 6}, \mathrm{RBS}_{\mathrm{C} 8}$ and $\mathrm{RBS}_{\mathrm{C} 9}$ ).

The engineered strains containing different expression vector had no limiting effects on the growth behavior. But the whole-cell catalytic activity for $\varepsilon$-caprolactone biosynthesis of cells containing different RBS sequences showed great differences. Generally speaking, the cells with higher $\mathrm{CHMO}$ enzyme activities presented better catalytic performance (Fig. 5 and Additional file 1: Fig. S3). When the $\mathrm{RBS}_{\mathrm{C} 0}$ was replaced by the $\mathrm{RBS}_{\mathrm{C} 5}$, 


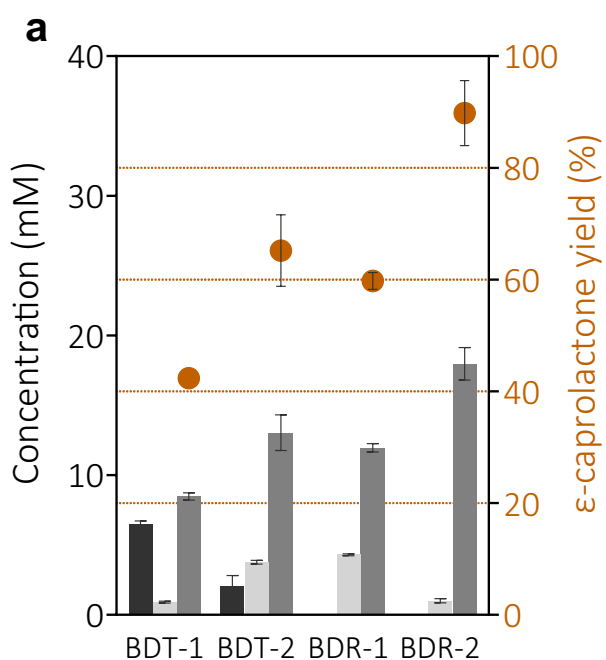

cyclohexanol cyclohexanone

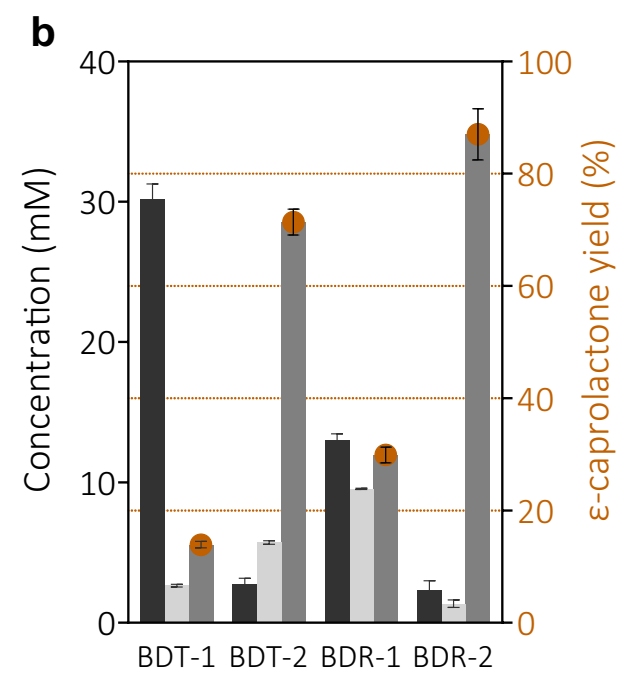

$\varepsilon$-caprolactone $\varepsilon$-caprolactone yield

Fig. 3 Whole-cell biocatalysis of $20 \mathrm{mM}$ (a) and $40 \mathrm{mM}$ (b) cyclohexanol into -caprolactone in $50 \mathrm{~mL}$ Erlenmeyer flasks containing $10 \mathrm{~mL}$ of cell catalysts (10 g/L WCW). Catalysis was carried out at $25^{\circ} \mathrm{C}$ for $16 \mathrm{~h}$. The data were expressed as mean values with standard deviations calculated from triplicate independent experiments

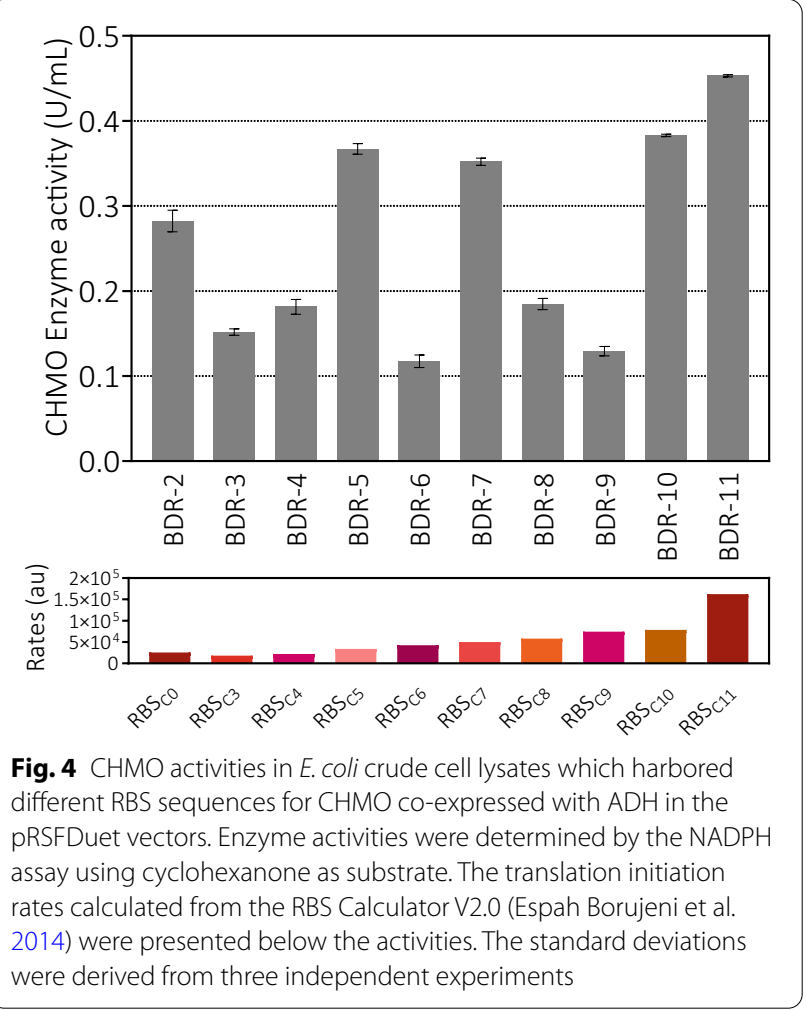

$\mathrm{RBS}_{\mathrm{C} 7}, \mathrm{RBS}_{\mathrm{C} 10}$, or $\mathrm{RBS}_{\mathrm{C} 11}$, the $\varepsilon$-caprolactone yields were improved to about $95.5 \pm 0.4 \%$ using $40 \mathrm{mM}$ cyclohexanol as substrate. With the enhancement of substrate concentration, the values of $\varepsilon$-caprolactone yield were reduced and the differences between them were gradually more significant. For the starter strain of BDR-2 with $\mathrm{RBS}_{\mathrm{C} 0}$ controlling CHMO expression, the $\varepsilon$-caprolactone yield was only about $22 \%$ with $80 \mathrm{mM}$ cyclohexanol as substrate after $16 \mathrm{~h}$ catalysis. For the other four optimized strains, the $\varepsilon$-caprolactone yields were in the range from 43.1 to $59.2 \%$. When the reaction time extended to $24 \mathrm{~h}$, the $\varepsilon$-caprolactone yields were further increased to $50.2-69.5 \%$. A dramatic decrease of conversion of cyclohexanol to $\varepsilon$-caprolactone was recorded at $60 \mathrm{mM}$ substrate concentration. This might be attributed to the inhibition by product or substrate to the CHMO (Kohl et al. 2018).

Above results show that the strain BDR-11 presented the best $\varepsilon$-caprolactone synthesis capability, which was equipped with $\mathrm{RBS}_{\mathrm{C} 11}$ at the putative T7 RNAP translation rate of $162,491.50 \mathrm{au}$. This $\mathrm{RBS}$ change from $\mathrm{RBS}_{\mathrm{C} 0}$ caused the activity ratio of $\mathrm{CHMO} / \mathrm{ADH}$ to rise from 0.34 to 0.66 . The relative balance of enzyme activities promoted the balance between the supply and consumption of $\operatorname{NADP}(\mathrm{H})$, thereby improving the tolerance of the cascade catalytic system to the substrate and the product conversion.

The ratios of NADPH/NADP ${ }^{+}$were determined in the strain BDR-2 and BDR-11 (Additional file 1: Table S5). In the initial stage of the whole-cell catalysis reaction, the ratios of NADPH/NADP ${ }^{+}$of the two strains were similar. After $16 \mathrm{~h}$ of catalytic reaction, a great change of cellular 

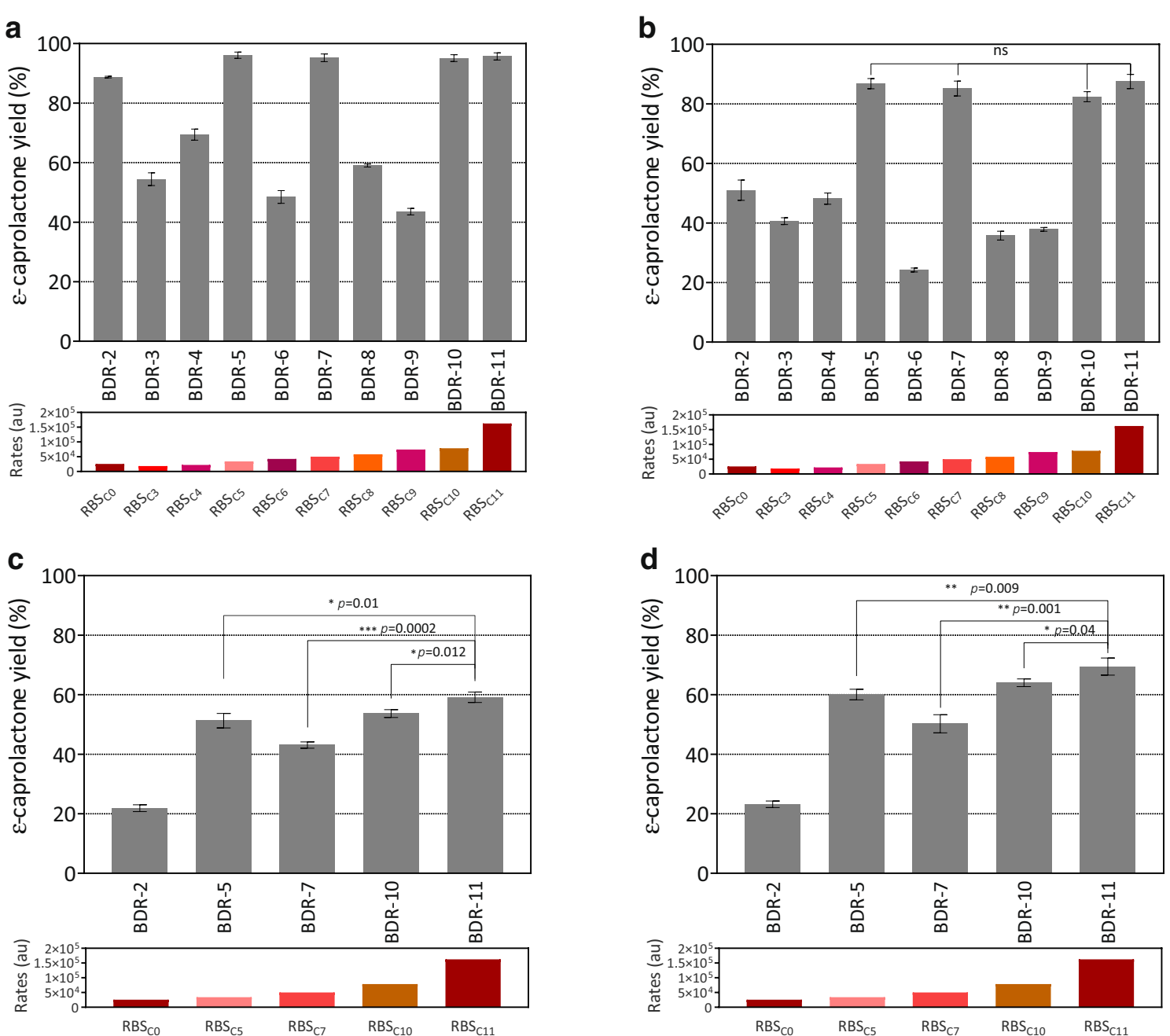

Fig. 5 Effect of different translate rates of RBSs on $\varepsilon$-caprolactone yields catalyzed by the E. coli BL21 (DE3) cells using 40 mM (a), 60 mM (b), 80 mM (c \& d) cyclohexanol as substrates. The whole-cell biocatalysis was carried out in triplicate at $25^{\circ} \mathrm{C}$ for $16 \mathrm{~h}(\mathbf{a}, \mathbf{b}$ and $\mathbf{c})$ and $24 \mathrm{~h}(\mathbf{d})$. Data were expressed as the mean values accompanied by the standard deviations. The significant analysis between the data was performed through multiple t tests by GraphPad Prism 8.0. ${ }^{*}, p<0.05,{ }^{* *}, p<0.01,{ }^{* * *}, p<0.001, \mathrm{~ns}$, not significant

$\mathrm{NADPH} / \mathrm{NADP}^{+}$ratio in BDR-2 was observed (from 0.105 to 0.138 ). For the strain BDR-11, the change of cytosolic NADPH/NADP ${ }^{+}$ratio was not significant. The results implied that BDR-11 displayed the better balance between the cofactor production and consumption.

\section{Production of $\varepsilon$-caprolactone}

As mentioned above, a substrate inhibition was found involved in the whole-cell bioconversion for $\varepsilon$-caprolactone production. The whole-cell biocatalysis was restricted by a high initial substrate concentration, which generally increases the process time and cost. To solve the problem, the production performance of the engineered strain BDR-11 was evaluated by whole-cell biocatalysis with a fed-batch strategy using resting cells. Batch reactions were carried out to produce $\varepsilon$-caprolactone by replacing $40 \mathrm{mM}$ cyclohexanol as substrate three times. As shown in Fig. 6, cyclohexanol was almost completely consumed to $\varepsilon$-caprolactone with a small amount of cyclohexanone detected in the first two reaction batches. The concentration of $\varepsilon$-caprolactone increased to approximately 37.9 and $74.7 \mathrm{mM}$, respectively. With increasing reaction time and the numbers of feedings, the biocatalytic abilities of the BDR-11 declined gradually. 7.4 mM of cyclohexanol was detected with an $88 \% \varepsilon$-caprolactone yield at the end of third reaction. The remaining cyclohexanol inhibited the further catalytic efficiency of the cells. After four batch reactions, the final concentration of $\varepsilon$-caprolactone reached at $126.0 \mathrm{mM}$ 




Fig. 6 Fed-batch production of $\varepsilon$-caprolactone through the whole-cell catalysis with resting cells. $40 \mathrm{mM}$ cyclohexanol was added into the reaction system every 16 h. $0.5-\mathrm{mL}$ samples were taken out for the concentration determination of cyclohexanol (black circle), cyclohexanone (black square) and $\varepsilon$-caprolactone (black triangle)

with a total yield of $78.8 \%$. To further evaluate the production performance of the engineered strain BDR-11, $60 \mathrm{mM}$ cyclohexanol was used in fed-batch catalysis subsequently. But the high concentration substrate may inhibit the activities of $\mathrm{CHMO}$ and $\mathrm{ADH}$, the conversion of cyclohexanol to $\varepsilon$-caprolactone was not high (Additional file 1: Fig. S4).

In previous studies, bioconversion for $\varepsilon$-caprolactone was reported using recombinant Pseudomonas taiwanensis (Karande et al. 2018), Geotrichum candidum (Silva et al. 2017) and E. coli cells by fed-batch (Kohl et al. 2018; Lee et al. 2007; Schmidt et al. 2015b) (Table 1). Among them, the maximum $\varepsilon$-caprolactone concentration of $134 \mathrm{mM}$ was obtained using cyclohexanone (245 $\mathrm{mM})$ as substrate by co-expression of glucose6-phosphate dehydrogenase at a high cell density ( $35 \mathrm{~g} / \mathrm{L}$ dried cells) (Lee et al. 2007). The recorded final conversion rate was about $54.7 \mathrm{~mol} / \mathrm{mol}$ cyclohexanone. In this study, only $10 \mathrm{~g} / \mathrm{L}$ wet cells achieved the catalytic process of converting $160 \mathrm{mM}$ cyclohexanol into $126.0 \mathrm{mM}$ $\varepsilon$-caprolactone. To our best knowledge, this is the highest catalytic efficiency for producing $\varepsilon$-caprolactone in the whole-cell batch reactions.

\section{Conclusions}

In this study, a route using whole-cell biocatalysis was designed to produce $\varepsilon$-caprolactone by cyclohexanol. With the help of RBS engineering, the expression levels of $\mathrm{ADH}$ and $\mathrm{CHMO}$ were fine-tuned to increase the operational efficiency. After optimization, an increase in the substrate tolerance was observed from 20 to $60 \mathrm{mM}$ in single batch catalysis. Finally, the high production of $\varepsilon$-caprolactone was achieved through fedbatch strategy. The construction of the strain (BDR-11) provides the possibility of industrial production of $\varepsilon$-caprolactone, and highlights the importance of controlling the cofactor of NADPH regeneration.

Table 1 Production of $\varepsilon$-caprolactone in different engineering host strains

\begin{tabular}{|c|c|c|c|c|c|c|c|}
\hline \multicolumn{2}{|l|}{ Cells } & \multicolumn{2}{|l|}{ Substrate } & \multirow{2}{*}{$\begin{array}{l}\varepsilon \text {-caprolactone } \\
\text { Concentration } \\
(\mathrm{mM})\end{array}$} & \multirow[t]{2}{*}{ Reaction } & \multirow{2}{*}{$\begin{array}{l}\text { Yield (mol/mol } \\
\text { substrate/cell } \\
\text { mass) }\end{array}$} & \multirow[t]{2}{*}{ References } \\
\hline Type & Mass (g/L) & Type & $\begin{array}{l}\text { Concentration } \\
\text { (mM) }\end{array}$ & & & & \\
\hline $\begin{array}{c}\text { Pseudomonas } \\
\text { taiwanensis }\end{array}$ & $6.8^{\mathrm{a}}$ & Cyclohexane & 200 & 17.0 & Single batch & $0.0125^{a}$ & (Karande et al. 2018) \\
\hline \multirow{2}{*}{$\begin{array}{l}\text { Geotrichum candi- } \\
\text { dum }\end{array}$} & \multirow[t]{2}{*}{100} & \multirow[t]{2}{*}{ Cyclohexanol } & 10 & 10 & Single batch & 0.0100 & \multirow[t]{2}{*}{ (Silva et al. 2017) } \\
\hline & & & 60 & 58.4 & Six batches & 0.0097 & \\
\hline E. coli & 10 & Cyclohexanol & $\begin{array}{r}60 \\
100\end{array}$ & $\begin{array}{l}36^{c} \\
28^{c}\end{array}$ & Single batch & $\begin{array}{l}0.0600 \\
0.0280\end{array}$ & (Kohl et al. 2018) \\
\hline \multirow[t]{2}{*}{ E. coli } & \multirow[t]{2}{*}{100} & \multirow[t]{2}{*}{ Cyclohexanol $^{\mathrm{b}}$} & 60 & $57^{c}$ & Single batch & 0.0095 & \multirow[t]{2}{*}{ (Schmidt et al. 2015b) } \\
\hline & & & 80 & $35^{c}$ & Single batch & 0.0044 & \\
\hline E. coli & $35^{\mathrm{a}}$ & Cyclohexanone & $245^{c}$ & 134 & Four batches & $0.0156^{\mathrm{a}}$ & (Lee et al. 2007) \\
\hline \multirow{3}{*}{ E. coli } & \multirow[t]{3}{*}{10} & \multirow[t]{3}{*}{ Cyclohexanol } & 60 & 47.7 & Single batch & 0.0795 & \multirow[t]{3}{*}{ This study } \\
\hline & & & 80 & 50.5 & Single batch & 0.0631 & \\
\hline & & & 160 & 126.0 & Four batches & 0.0788 & \\
\hline
\end{tabular}

\footnotetext{
${ }^{a}$ Dry cell mass concentration

${ }^{\mathrm{b}}$ Reaction mixtures were supplemented with equimolar amount of D-glucose and/or acetone for cofactor recycling

${ }^{\mathrm{C}}$ Calculated from figures in the literature
} 


\section{Abbreviations}

$\mathrm{ADH}$ : Alcohol dehydrogenase; CHMO: Cyclohexanone monooxygenase; NADH: Nicotinamide adenine dinucleotide; NADPH: Nicotinamide adenine dinucleotide phosphate; RBS: Ribosome binding site; IPGT: Isopropyl $\beta$-D-1thiogalactopyranoside; SDS-PAGE: Sodium dodecyl sulfate-polyacrylamide gel electrophoresis; DMSO: Dimethyl sulfoxide; LB: Luria-Bertani medium; WCW : Wet cell weight; GC: Gas chromatography; FID: Flame-ionization detector; GC-MS: Chromatography coupled to mass spectrometry; MSD: Mass selective detector.

\section{Supplementary Information}

The online version contains supplementary material available at https://doi. org/10.1186/s40643-021-00370-w.

Additional file 1: Fig. S1. Analysis and identification of cyclohexanol, cyclohexanone and $\varepsilon$-caprolactone. (A) GC-FID chromatogram pattern of standards. Retention times of acetophenone, cyclohexanol, cyclohexanone and $\varepsilon$-caprolactone were 7.444, 7.648, 12.158 and $10.745 \mathrm{~min}$, respectively. Mass spectra of cyclohexanol (B), cyclohexanone (C) and $\varepsilon$-caprolactone (D) were compared with the authentic standards. Fig. S2. SDS-PAGE analysis of recombinant E. coli cells when the RBS sequences controlling CHMO expression on pRSFDuet-1 were altered. Strains from BDR-02 to BDR-11 were abbreviated from 02 to 11 . Fig. S3. Effects of different RBS sequences on the production of $\varepsilon$-caprolactone using different concentrations of cyclohexanol as substrates catalyzed for different hours. (A) 40 mM, 16 h; (B) 60 mM, 16 h; (C) 80 mM, 16 h; (D) 80 mM, 24 $h$. The calculated translation rates were also presented. Three independent experiments were performed. Fig. S4. Fed-batch production of $\varepsilon$-caprolactone through the whole-cell biocatalysis. $60 \mathrm{mM}$ cyclohexanol was added into the reaction system every $20 \mathrm{~h} .0 .5 \mathrm{~mL}$ samples were taken out for the concentration determination of cyclohexanol (Black circle), cyclohexanone (Black square) and $\varepsilon$-caprolactone (Black triangle). Table S1. Recombinant E. coli BL21(DE3) strains and plasmids used in this study. Table S2. Primers used in this study. Table S3. The designed ribosome binding sites of $\mathrm{CHMO}$ and $\mathrm{ADH}$ genes and their predicted translation initiation rates. Table S4. The measured final OD600 of the engineered strains before centrifugation for harvest. All experiments were performed in triplicates. Table S5. Changes of cellular NADPH/NADP+ ratios in BDR-2 and BDR-11*

\section{Acknowledgements}

Not applicable.

\section{Author contributions}

JHX, HFC and SL conceived the idea and plan of this project. JHX and HFC performed most of the experiments. RL performed part of the experiments in construction of dual-expression vectors. HY, MZ, TZ and SL supervised the whole research and revised the manuscript. All authors read and approved the final manuscript.

\section{Funding}

We are grateful for the financial support of this work by the National Key R\&D Program of China (2018YFA0901504), the Natural Science Foundation of China (Grants 21878104 and U1701243), the Project on the Integration of Industry, Education, and Research of Guangzhou, China (Grants 201903010086). Shuang Li was awarded by the Young Talents in Scientific and Technological Innovation of the Special Support Plan for the Cultivation of High-Level Talents in Guangdong.

\section{Availability of data and materials}

The datasets used and/or analyzed during the current study are available from the corresponding author on reasonable request.

\section{Ethics approval and consent to participate} Not applicable.

\section{Consent for publication}

Not applicable.

\section{Competing interests}

The authors declare that they have no competing interests.

\section{Author details}

${ }^{1}$ School of Biology and Biological Engineering, South China University of Technology, Higher Education Mega Center, Guangzhou 510006, China. ${ }^{2}$ School of Chemistry and Chemical Engineering, South China University of Technology, Guangzhou 510006, China.

Received: 19 November 2020 Accepted: 11 February 2021

Published online: 22 April 2021

\section{References}

Ban N, Nissen P, Hansen J et al (2000) The complete atomic structure of the large ribosomal subunit at $2.4 \AA$ resolution. Science 289:905-920

Espah Borujeni A, Channarasappa AS, Salis HM (2014) Translation rate is controlled by coupled trade-offs between site accessibility, selective RNA unfolding and sliding at upstream standby sites. Nucleic Acids Res 42:2646-2659

France SP, Hepworth LJ, Turner NJ et al (2017) Constructing biocatalytic cascades: in vitro and in vivo approaches to de novo multi-enzyme pathways. ACS Catalysis 7:710-724

Gandomkar S, Żądło-Dobrowolska A, Kroutil W (2019) Extending designed linear biocatalytic cascades for organic synthesis. ChemCatChem $11: 225-243$

Hildebrand F, Kohlmann C, Franz A et al (2008) Synthesis, characterization and application of new rhodium complexes for indirect electrochemical cofactor regeneration. Adv Synth Catal 350:909-918

Hollmann F, Arends IWCE, Holtmann D (2011) Enzymatic reductions for the chemist. Green Chem 13:2285-2314

Karande R, Salamanca D, Schmid A et al (2018) Biocatalytic conversion of cycloalkanes to lactones using an in-vivo cascade in Pseudomonas taiwanensis VLB120. Biotechnol Bioeng 115:312-320

Kohl A, Srinivasamurthy V, Bottcher D et al (2018) Co-expression of an alcohol dehydrogenase and a cyclohexanone monooxygenase for cascade reactions facilitates the regeneration of the NADPH cofactor. Enzyme Microb Technol 108:53-58

Lee WH, Park JB, Park K et al (2007) Enhanced production of $\boldsymbol{\varepsilon}$-caprolactone by overexpression of NADPH-regenerating glucose 6-phosphate dehydrogenase in recombinant Escherichia coli harboring cyclohexanone monooxygenase gene. Appl Microbiol Biotechnol 76:329-338

Mallin H, Wulf H, Bornscheuer UT (2013) A self-sufficient Baeyer-Villiger biocatalysis system for the synthesis of $\boldsymbol{\varepsilon}$-caprolactone from cyclohexanol. Enzyme Microb Technol 53:283-287

Ménil S, Petit J-L, Courvoisier-Dezord E et al (2019) Tuning of the enzyme ratio in a neutral redox convergent cascade: a key approach for an efficient one-pot/two-step biocatalytic whole-cell system. Biotechnol Bioeng 116:2852-2863

Milker S, Goncalves LCP, Fink MJ et al (2017) Escherichia coli fails to efficiently maintain the activity of an important flavin monooxygenase in recombinant overexpression. Front Microbiol 8

De Novo DNA (2018) https://salislab.net/software/. Accessed 20 Oct 2018

Pathak VM, Navneet (2017) Review on the current status of polymer degradation: a microbial approach. Biores Bioprocessing 4

Quinto T, Köhler V, Ward TR (2014) Recent trends in biomimetic NADH regeneration. Top Catal 57:321-331

Salis HM, Mirsky EA, Voigt CA (2009) Automated design of synthetic ribosome binding sites to control protein expression. Nat Biotechnol 27:946-950

Scherkus C, Schmidt S, Bornscheuer UT et al (2016) A fed-batch synthetic strategy for a three-step enzymatic synthesis of poly- $\varepsilon$-caprolactone. ChemCatChem 8:3446-3452

Scherkus C, Schmidt S, Bornscheuer UT et al (2017) Kinetic insights into $\varepsilon$-caprolactone synthesis: improvement of an enzymatic cascade reaction. Biotechnol Bioeng 114:1215-1221

Schmidt S, Büchsenschütz HC, Scherkus C et al (2015a) Biocatalytic access to chiral polyesters by an artificial enzyme cascade synthesis. ChemCatChem 7:3951-3955

Schmidt S, Scherkus C, Muschiol J et al (2015b) An enzyme cascade synthesis of $\varepsilon$-caprolactone and its oligomers. Angew Chem Int Edit 54:2784-2787 
Silva ALP, Batista PK, Filho AD et al (2017) Rapid conversion of cyclohexenone cyclohexanone and cyclohexanol to $\varepsilon$-caprolactone by whole cells of Geotrichum candidum CCT 1205. Biocatal Biotransfor 35:185-190

Spaans S, Weusthuis R, VanDer OJ et al (2015) NADPH-generating systems in bacteria and archaea. Front Microbiol. https://doi.org/10.3389/fmicb. 2015.00742

Staudt S, Bornscheuer UT, Menyes U et al (2013) Direct biocatalytic onepot-transformation of cyclohexanol with molecular oxygen into $\boldsymbol{\varepsilon}$-caprolactone. Enzyme Microb Technol 53:288-292

Sun T, Li B, Nie Y et al (2017) Enhancement of asymmetric bioreduction of N,N-dimethyl-3-keto-3-(2-thienyl)-1-propanamine to corresponding (S)enantiomer by fusion of carbonyl reductase and glucose dehydrogenase. Bioresources and Bioprocessing 4

ten Brink GJ, Arends IWCE, Sheldon RA (2004) The Baeyer-Villiger reaction: new developments toward greener procedures. Chem Rev 104:4105-4124

Tolia NH, Joshua-Tor L (2006) Strategies for protein coexpression in Escherichia coli. Nat Methods 3:55-64

Wang M, Chen B, Fang Y et al (2017a) Cofactor engineering for more efficient production of chemicals and biofuels. Biotechnol Adv 35:1032-1039

Wang X, Saba T, Yiu HHP et al (2017b) Cofactor NAD(P)H regeneration inspired by heterogeneous pathways. Chem 2:621-654
Weckbecker A, Gröger H, Hummel W (2010) Regeneration of nicotinamide coenzymes: principles and applications for the synthesis of chiral compounds. In: Wittmann C, Krull R (eds) Biosystems engineering I: creating superior biocatalysts. Springer, Berlin, Heidelberg

Willetts AJ, Knowles CJ, Levitt MS et al (1991) Biotransformation of endobicyclo[2.2.1] heptan-2-ols and endo-bicyclo[3.2.0]hept-2-en-6-ol into the corresponding lactones. J Chem Soc Perk T 1:1608-1610

Wu H, Tian C, Song X et al (2013) Methods for the regeneration of nicotinamide coenzymes. Green Chem 15:1773-1789

Xu MQ, Li FL, Yu WQ et al (2019) Combined cross-linked enzyme aggregates of glycerol dehydrogenase and NADH oxidase for high efficiency in situ $\mathrm{NAD}^{+}$regeneration. Int J Biol Macromol 144:1013-1021

Zhang C, Song W, Liu J et al (2019) Production of enantiopure (R)-or (S)2-hydroxy-4-(methylthio)butanoic acid by multi-enzyme cascades. Biores Bioprocess. https://doi.org/10.1186/s40643-019-0244-x

\section{Publisher's Note}

Springer Nature remains neutral with regard to jurisdictional claims in published maps and institutional affiliations.

\section{Submit your manuscript to a SpringerOpen ${ }^{\circ}$ journal and benefit from:}

- Convenient online submission

- Rigorous peer review

- Open access: articles freely available online

- High visibility within the field

- Retaining the copyright to your article

Submit your next manuscript at $\boldsymbol{\nabla}$ springeropen.com 